\title{
Does Our Vision of Diversity Reduce Harm and Promote Justice?
}

Benjamin Keisling*, Raquel Bryant, Dept. of Geosciences, Univ. of Massachusetts, 627 North Pleasant Street, Amherst, Massachusetts 01003, USA; Nigel Golden, Dept. of Environmental Conservation, Univ. of Massachusetts, 160 Holdsworth Way, Amherst, Massachusetts 01003, USA; Laura A. Stevens**, Marine Geology and Geophysics, Lamont-Doherty Earth Observatory, 61 Route 9W, Palisades, New York 10964, USA; and Ellen Alexander, Dept. of Earth, Planetary, and Space Sciences, Univ. of California, 595 Charles Young Drive, Los Angeles, California 90095, USA

Geoscientists have a unique responsibility to cultivate diversity among our ranks. First, geoscience is the least diverse STEM field, so we have the most room for improvement (NSF, 2019). Second, our field faces a workforce shortage, despite growing demand for our expertise, due to the lack of robust mechanisms to recruit, train, and retain diverse cohorts (Wilson, 2014). Third, calling Earth "home" is perhaps the only common experience between all people and thus access to understanding and appreciating Earth must not be limited by societal inequities. Decades of concerted efforts to broaden participation of marginalized groups in geoscience have resulted in no progress on a demographic scale (Bromery et al., 1972; Bernard and Cooperdock, 2018). Therefore, we must go above and beyond if we stand a chance of fulfilling our responsibility.

Here we argue that efforts to advance diversity, equity, and inclusion (DEI) in the geosciences must be rooted in a common understanding of the role of harm and justice in our vision of diversity. We provide three principles and a set of recommendations that are widely applicable and relevant to the cultural and historical specificities of our field.

\section{PRINCIPLE 1. EVERYONE BENEFITS FROM A DIVERSE, VIBRANT GEOSCIENCE COMMUNITY THAT CENTERS OUR MOST MARGINALIZED MEMBERS}

Guiding frameworks for maximizing the efficacy of DEI efforts can be found in the literature. Much of this work rejects the premise that the inclusion of one group necessarily comes at the expense of others, a pervasive myth that is especially harmful to geoscientists who claim multiple marginalized identities (e.g., Mattheis et al., 2019). That dimensions of diversity are interconnected is central to Kimberlé Crenshaw's seminal analysis of Black women's experience, where she coined the term intersectionality (Crenshaw, 1989). In fact, Núñez et al. (2019) leveraged this theoretical concept to develop geoscience-specific recommendations for practicing intersectionality toward greater equity.

Rather than the inclusion of one group resulting in the exclusion of another, intersectionality posits that DEI work centering individuals who are the most marginalized results in greater inclusion for everyone (Crenshaw, 1989). An intersectional approach to DEI asks that we invest our energy in removing the barriers to participation for people who have multiple underrepresented or marginalized identities: those who are most at risk of being excluded.

\section{PRINCIPLE 2. THE ROAD TO INCLUSION IS UNCOMFORTABLE FOR EVERYONE-THE MAJORITY AND THE MARGINALIZED}

We must not conflate being uncomfortable with being marginalized. Harm is inseparable from, and central to, marginalization. Therefore, the reduction of harm must be prioritized in our DEI work. A recent example from the geosciences illustrates this distinction. Last fall, advertisements for a faculty job in Brigham Young University's (BYU) geology department were removed from numerous job boards because BYU's honor code, which prohibited "homosexual behavior," was found to be incompatible with the diversity statements of several international organizations, the Geological Society of America (GSA) included. Some BYU faculty members saw this removal as its own kind of discrimination (Abbott et al., 2019). The identities and perspectives of $\mathrm{LGBTQ}^{+}$people cannot be separated from their lived experiences of harm. Discriminating against LGBTQ+ people in hiring is part of a larger system of discrimination that results in higher rates of harm, including homelessness, attempted suicide, and murder (Durso and Gates, 2012; Human Rights Campaign, 2015; Dinno, 2017). Our principles provide a way to distinguish separate experiences of harm and discomfort: an honor code violation may be uncomfortable, but does not cause harm.

Alternative frameworks, for example those that center on treating people with "love" and/ or "kindness," obscure the fact that difference is not innate but emerges within a network of established power relationships (Hearn and Louvrier, 2016). As we dismantle systems of oppression in geoscience, having opinions that conflict with the core goals of inclusion will be uncomfortable. This is not marginalization, and reckoning with our discomfort moves us toward greater inclusion.

\section{PRINCIPLE 3. WE CANNOT ASK MARGINALIZED PEOPLE TO DO THE WORK TO ENSURE THEY ARE INCLUDED}

Inclusion must not require that people advocate for themselves, their own rights, or their own humanity. As Black queer writer and activist Audre Lorde laments, "It is the members of the oppressed, objectified groups

GSA Today, v. 30, https://doi.org/10.1130/GSATG429GW.1. Copyright 2020, The Geological Society of America. CC-BY-NC.

* Now at Lamont-Doherty Earth Observatory, Columbia University, Palisades, New York 10964, USA.

** Now at Dept. of Earth Sciences, University of Oxford, Oxford OX1 3AN, UK. 
who are expected to reach out and bridge the actualities of our lives and the consciousness of our oppressor. ... Whenever the need for some pretense of communication arises, those who profit from our oppression call upon us to share our knowledge with them. In other words, it is the responsibility of the oppressed to teach the oppressors their mistakes" (Lorde, 1984, p. 114). Rather than rely on this limiting, exploitative model, we must anticipate the needs of diverse communities and proactively meet them. To put it differently, a coherent framework for inclusion need never be expanded to cover new groups - rather, it critically examines existing structures that prohibit broader participation and dismantles them. In this way, representation and inclusion fundamentally differ. For example, the presence of an LGBTQ+ faculty member may help LGBTQ+ students feel a sense of belonging (Yoder and Mattheis, 2015). Yet, a department or organization does not need to hire an LGBTQ+ faculty member in order to be inclusive of LGBTQ+ people. In fact, such an approach reduces someone along a singular axis of their identity and expects them to represent a community whose experiences are manifold. A wide variety of resources, including on-campus groups, national affinity networks, and professional organizations provide suggestions about making a department more inclusive of marginalized people. We should use them.

\section{WHERE DO WE GO FROM HERE?}

Geosciences departments, professional societies, and funding agencies are reaffirming their commitments to DEI. But the discourse is muddled by the lack of a shared framework for what it means and why we pursue it. We have identified broadly applicable principles to form the core of a coherent, sustainable, and effective model of inclusion. There are also many hopeful and effective examples of how you can advance DEI goals:

1. Leverage your position and privilege to improve your community. Identify contexts in which you personally have power and influence. Be it a meeting with administrators, the graduate student union, or sorority, we all inhabit spaces where our voices are valued. Share your interest in advancing DEI in the geosciences within these spaces, and use your influence there to motivate others.
2. Practice inclusive pedagogy. Just like we engage with scholarly literature to inform our understanding of our geological subfields, a vast literature on DEI exists that can inform our efforts in this space. Start a for-credit seminar or reading group to ignite and continue the conversation.

3. Become a DEI leader. Organize for change and get involved on your own campus (see efforts by graduate students at the University of Massachusetts Amherst, https://eos.org/opinions/whats-in-a-seminar), within a broader affinity group (see the GeoLatinas: https://twitter.com/geolatinas), or with an international professional organization (volunteer for a leadership/diversity position with, for example, GSA, the American Geophysical Union (AGU), or the American Meteorological Society).

4. Hold institutions accountable to their most vulnerable members. The successful social media campaign (Tanner, 2019) to remove the BYU job advertisement from the GSA and AGU job boards because it was inconsistent with the associations' commitments to diversity and inclusion demonstrates the power that individuals have to effect change, especially when we uplift and amplify marginalized voices.

All institutions have room to improve with regard to broadening participation, but half a century of efforts to diversify the geosciences have been stonewalled by myriad obstacles (Bromery et al., 1972; Bernard and Cooperdock, 2018). We cannot expect that rearticulating the same tired commitments will result in a different outcome. Instead, we must be bold and brave in pursuit of our goals. Use the principles laid out here to inform the everyday decisions that over time create the fabric of geoscience culture we inhabit. The responsibility to fulfill our vision of diversity falls to every one of us. What action will you take to achieve it?

\section{ACKNOWLEDGMENTS}

We thank two anonymous reviewers and editor Mihai Ducea for feedback that improved the manuscript.

\section{REFERENCES CITED}

Abbott, B., Radebaugh, J., and Jensen, J.L., 2019, Does our vision of diversity include social conservatives?: Eos (Washington, D.C.), v. 100, https://doi.org/10.1029/2019EO136069.

Bernard, R.E., and Cooperdock, E.H., 2018, No progress on diversity in 40 years: Nature Geosci- ence, v. 11, p. 292-295, https://doi.org/10.1038/ s41561-018-0116-6.

Bromery, R.W., et al., 1972, Minorities in the geosciences: American Geological Institute: Geotimes, v. 17, no. 2, p. 23-24.

Crenshaw, K., 1989, Demarginalizing the Intersection of Race and Sex: A Black Feminist Critique of Antidiscrimination Doctrine, Feminist Theory and Antiracist Politics: University of Chicago Legal Forum, v. 1989, v. 1.

Dinno, A., 2017, Homicide rates of transgender individuals in the United States: 2010-2014: American Journal of Public Health, v. 107, p. 1441-1447, https://doi.org/10.2105/AJPH.2017.303878.

Durso, L.E., and Gates, G.J., 2012, Serving Our Youth: Los Angeles, California, The Williams Institute with True Colors Fund and The Palette Fund.

Hearn, J., and Louvrier, J., 2016, Theories of Difference, Diversity, and Intersectionality: Oxford, UK, Oxford University Press, https://doi.org/10.1093/ oxfordhb/9780199679805.013.28

Human Rights Campaign in partnership with Trans People of Color Coalition, 2015, Addressing Anti-Transgender Violence: Exploring Realities, Challenges and Solutions for Policymakers and Community Advocates: https:// assets2.hrc.org/files/assets/resources/HRC -AntiTransgenderViolence-0519.pdf.

Lorde, A., 1984, Age, race, class and sex: Women redefining difference, in Lorde, A., ed., Sister Outsider: Berkeley, California, Crossing Press, $192 \mathrm{p}$.

Mattheis, A., Cruz-Ramírez De Arellano, D., and Yoder, J.B., 2019, A model of queer STEM identity in the workplace: Journal of Homosexuality, p. 1-25, https://doi.org/10.1080/00918369.2019 .1610632 .

Núñez, A.-M., Rivera, J., and Hallmark, T., 2019, Applying an intersectionality lens to expand equity in the geosciences: Journal of Geoscience Education, v. 68, p. 97-114, https://doi.org/10.1080/ 10899995.2019.1675131.

NSF, 2019, Women, Minorities, and Persons with Disabilities in Science and Engineering: 2019: Alexandria, Virginia, National Science Foundation Special Report NSF 19-304.

Tanner, C., 2019, Two science societies removed BYU job postings over the school's honor code ban on 'homosexual behavior': The Salt Lake Tribune, 11 Nov. 2019, https://www.sltrib.com/ news/education/2019/11/11/two-science-societies/ (accessed 3 Aug. 2020).

Wilson, C.E., 2014, Explanation of the Predicted Geoscience Workforce Shortage: Geoscience Currents, v. 93.

Yoder, J.B., and Mattheis, A., 2015, Queer in STEM: Workplace experiences reported in a national survey of LGBTQA individuals in science, technology, engineering, and mathematics careers: Journal of Homosexuality, v. 63, p. 1-27, https://doi.org/10.1080/00918369.2015.1078632.

Manuscript ReCeived 17 Nov. 2019

REVISED MANUSCRIPT RECEIVED 8 JUNE 2020

ManUSCRIPT ACCEPTED 21 July 2020 